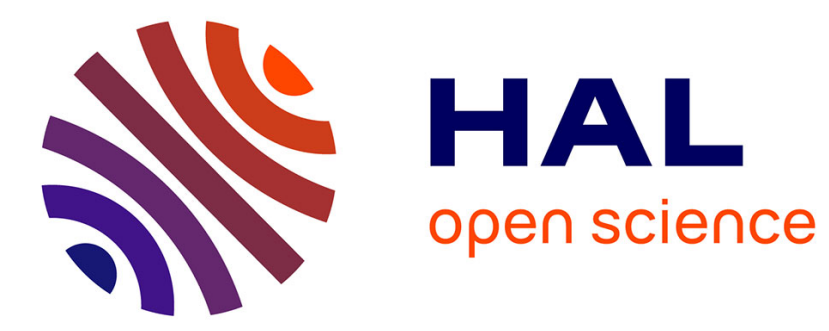

\title{
Mixed mode II and III fatigue crack growth in a rail steel
}

\author{
Thomas Bonniot, Véronique Doquet, Si Hai Mai
}

\section{To cite this version:}

Thomas Bonniot, Véronique Doquet, Si Hai Mai. Mixed mode II and III fatigue crack growth in a rail steel. International Journal of Fatigue, 2018, Crack tip fields 4, 115, pp.42-52. 10.1016/j.ijfatigue.2018.01.010 . hal-01820021

\section{HAL Id: hal-01820021 \\ https://hal.science/hal-01820021}

Submitted on 13 Jul 2021

HAL is a multi-disciplinary open access archive for the deposit and dissemination of scientific research documents, whether they are published or not. The documents may come from teaching and research institutions in France or abroad, or from public or private research centers.
L'archive ouverte pluridisciplinaire HAL, est destinée au dépôt et à la diffusion de documents scientifiques de niveau recherche, publiés ou non, émanant des établissements d'enseignement et de recherche français ou étrangers, des laboratoires publics ou privés. 


\section{Accepted Manuscript}

Mixed mode II and III fatigue crack growth in a rail steel.

Thomas Bonniot, Véronique Doquet, Si Hai Mai

PII: $\quad$ S0142-1123(18)30010-0

DOI: $\quad$ https://doi.org/10.1016/j.ijfatigue.2018.01.010

Reference: $\quad$ JIJF 4539

To appear in: $\quad$ International Journal of Fatigue

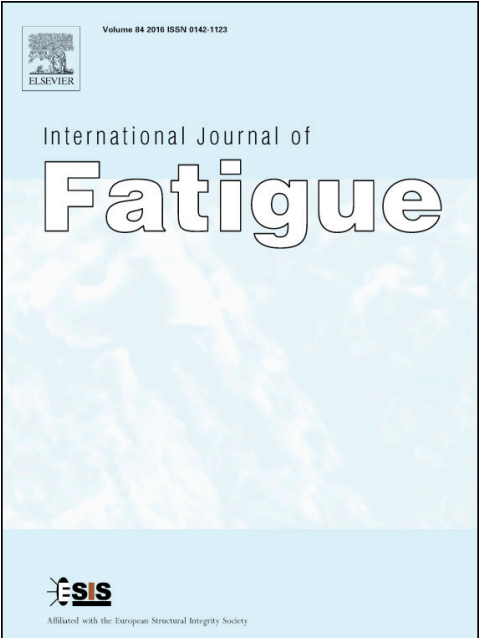

Accepted Date: $\quad 9$ January 2018

Please cite this article as: Bonniot, T., Doquet, V., Mai, S.H., Mixed mode II and III fatigue crack growth in a rail steel., International Journal of Fatigue (2018), doi: https://doi.org/10.1016/j.ijfatigue.2018.01.010

This is a PDF file of an unedited manuscript that has been accepted for publication. As a service to our customers we are providing this early version of the manuscript. The manuscript will undergo copyediting, typesetting, and review of the resulting proof before it is published in its final form. Please note that during the production process errors may be discovered which could affect the content, and all legal disclaimers that apply to the journal pertain. 


\title{
Mixed mode II and III fatigue crack growth in a rail steel.
}

\author{
Thomas Bonniot $^{\mathrm{a}, \mathrm{b}}$, Véronique Doquet ${ }^{\mathrm{a}, *}$, Si Hai Mai ${ }^{\mathrm{b}}$ \\ ${ }^{a}$ Laboratoire de Mécanique des Solides, CNRS, UMR 7649, Université Paris-Saclay, Ecole Polytechnique, 91120 Palaiseau, \\ France \\ ${ }^{b}$ SNCF Innovation and Research, 44 avenue des Terroirs de France, 75012 Paris, France
}

\begin{abstract}
Rolling contact fatigue cracks in rails undergo non-proportional mixed-mode $\mathrm{I}+\mathrm{II}+\mathrm{III}$, in variable proportions along their front. In order to determine the crack growth thresholds and kinetics in mixed-mode II/III, asymmetric four point bending tests are run on a rail steel with different angles between the crack front and the shearing load, so as to vary the mode mixity ratio. For sufficiently high loading ranges, these tests give rise to coplanar shear-mode crack growth. The effective stress intensity factors (SIFs) are derived by an inverse method from the measured crack face relative displacements. It appears to be 10-70\% lower than the nominal SIFs and to allow a reasonable correlation of the measured crack growth rates. The local application, ahead of the crack front, of shear-driven or tension-driven fatigue damage models -after 3D elastic-plastic computations of local stress and strain ranges- allows a successful prediction of crack fronts paths and growth rates.
\end{abstract}

Keywords: Fatigue crack, mode II, mode III, friction, rail steel

\section{Introduction}

The repeated passage of train wheels induces fatigue cracks in rails. Those surface cracks are loaded in non proportional mixed mode $\mathrm{I}+\mathrm{II}+\mathrm{III}$ in variable proportions along their front $[1-3]$. This makes the prediction of the crack path and growth rate challenging, since there is no commonly accepted bifurcation criterion nor crack growth kinetic law for this type of loading. Those cracks initiate at the contact surface between the rail and train wheel, due to very high cumulated plastic shear strains, and first propagate through the plastically-deformed layer in a direction controlled by the strong shear-induced microstructural anisotropy $[4,5]$. At a few millimeters in depth, the cracks leave this plastically deformed layer and their subsequent growth is the object of this study.

For a "squat" type defect deeper than $6 \mathrm{~mm}, 3 \mathrm{D}$ numerical simulations reported in $[2,3]$ show that the amplitude of shear mode loadings (mode II and III) is 2 to 10 times higher than that of mode I. However, while usual bifurcation criteria predict crack tilting at $\approx 70^{\circ}$ for mode II and twisting at $45^{\circ}$ for mode III

\footnotetext{
${ }^{*}$ Corresponding author.

Email adress: veronique.doquet@polytechnique.edu
}

[6], squat-type cracks do not bifurcate immediately when they leave the plastically-deformed layer, but continue to grow along a highly sheared plane, over a significant distance. At a given point along their front, $K_{I I}$ and $K_{I I I}$ exhibit more or less proportional time evolutions, but their proportions vary along the crack front. A first step in the experimental study of crack propagation in rails is thereby to perform proportional mixed mode II/III experiments in order to get kinetic data and thresholds for coplanar growth in shear modes or bifurcation, as predicted by usual criteria [6].

Several studies focussed on pure mode II [7-13] or on pure mode III [14-17]. It was shown: 1) that crack face interlocking and friction, which reduce the effective shear-mode singularities, and induce some mode I, due to a dilatancy effect [18], cannot be neglected and 2) that for sufficiently high effective $\Delta K_{I I}$ or $\Delta K_{I I I}$, fatigue cracks grow macroscopically coplanar, in what Brown, Miller et al. [19] called "Stage III", instead of branching, as predicted by the usual bifurcation criteria [6].

However, fatigue crack growth in rails implies combined mode II and III. To the author's knowledge, only a few studies focussed on this type of loading. 
Pokluda, Vojtek et al. [20-25] used cylindrical specimens with a circumferential notch (or two circumferential notches) on which a cyclic transverse shear force was applied. This device provides different mode mixity ratios $K_{I I} / K_{I I I}$ along the crack front, which allows comparisons of crack growth mechanisms and thresholds in mode II and mode III from one experiment. After the tests, the sample is broken in mode I, and the extent of shear-mode crack growth can be measured by SEM, but crack growth cannot be monitored during the experiment, and friction effects cannot be evaluated because crack face sliding displacement profiles cannot be measured. In [2025], crack face friction was prevented -but only for the early stage of crack growth- by compressive precracking, which induced some residual crack opening, and the studies focused on the thresholds, and near-threshold propagation mechanisms. Austenitic stainless steel, ARMCO iron, $\alpha$-titanium, nickel and nobium were studied. For each of those materials, the measured mode II threshold was smaller than the mode III threshold (by a factor 1.7 for stainless steel, ARMCO iron, $\alpha$-titanium and nickel [22]), and the crack growth rate was larger for mode II than for mode III. Near-threshold kinetic data were obtained for ARMCO iron and plotted versus a $\Delta K_{\text {equivalent }}$ [26]. It appeared again that mode III was less efficient than mode II for crack growth. For nobium and titanium, cracks subjected to near-threshold mode III grew by local mode II, which explained the slower crack growth and higher threshold for mode III [27].

Fremy, Pommier et al. [28] combined mode I, II and III on cruciform specimens loaded both inplane and out-of-plane. They mostly focused on crack growth kinetics, depending on the loading path. Crack face friction was prevented by a positive $K_{I}$. Their experimental device allows a direct monitoring of crack growth, but a triaxial testing machine is needed, and the control of mode III, applied through a point contact on the surface of the specimen, is a challenge.

Hellier et al. [29-32] developed an asymmetric four point bending device, and used beams, with a waisted central part and a straight central notch. By rotating the sample around an horizontal axis, one changes the orientation of the notch relative to the vertical shear force, hence changing the proportions of mode II and mode III. After the test, the specimens are broken in mode I in order to measure the extent of shear mode crack growth by SEM. In [30],
Hellier et al. performed tests on a rail steel. No precracking was performed, and the gradient in mode mixity along the crack front was ignored. The reported thresholds were $\Delta K_{I I t h}=15 \pm 1.1 \mathrm{MPa} \sqrt{m}$ and $\Delta K_{\text {IIIth }}=18.8 \pm 2.0 \mathrm{MPa} \sqrt{m}$ for a load ratio $R=0$. Again, the threshold for mode II was smaller than that for mode III. No coplanar growth was observed, but the cracks propagated at $\approx 70^{\circ}$ relative to the notch in mode II, and exhibited a factory roof pattern at $\pm 45^{\circ}$ in mode III, as predicted by the maximum tangential stress criterion [6].

Doquet et al. [33] performed mixed-mode II + III crack growth experiments on maraging steel and Ti-6Al-4V, using the same device as Hellier et al. 3D FEM computations [33] showed that for any position of the sample on the test rig, the mode mixity actually varies significantly along the crack front, which has to be taken into account in the analysis of experimental data. Crack growth was monitored on both side surfaces, and crack face sliding displacement profiles were measured, so as to evaluate the effective SIFs, allowance made for friction effects. Kinetic data were obtained for maraging steel and Ti-6Al-4V, and plotted versus a $\Delta K_{\text {equivalent. It appeared that for both }}$ materials, mode III was less efficient than mode II for "stage III" coplanar shear mode crack growth.

The aim of the present study is to obtain intrinsic, friction-corrected mixed-mode II + III crack growth kinetics for a rail steel. The same asymmetric 4 point bending device was used. Section 2 will introduce the experimental and numerical procedures, section 3 will summarize the results, and section 4 will show that the crack path and the extent of coplanar shear mode crack growth can actually be predicted by the local application, ahead of the crack front, of critical plane fatigue damage models, previously identified from biaxial fatigue tests, as detailed in appendix Appendix B.

\section{Experimental setup and numerical proce- dure}

The experimental setup consists of a waisted bar with a central section of $10 \mathrm{~mm} * 10 \mathrm{~mm}$ submitted to asymmetric bending (Fig. 1). This bar has a notch and a precrack in the middle of its length, where there is no bending moment, and thus no mode I, but a shear force, which induces shear modes on the crack. The sample can be rotated around an hori- 


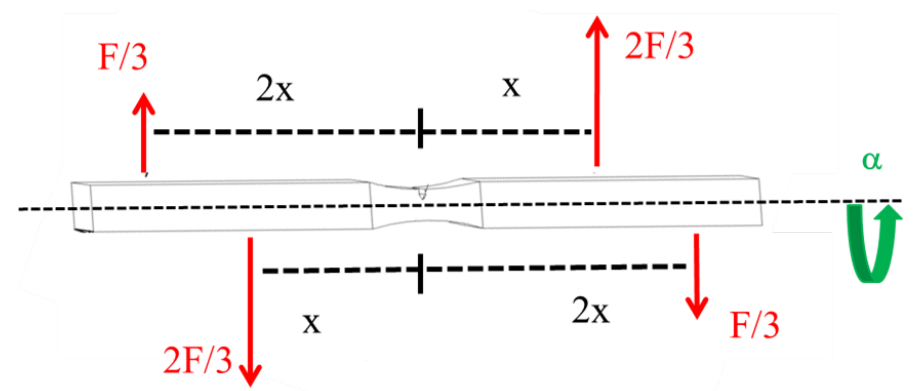

Figure 1: Asymmetric four point bending device. $x=41.25$ $\mathrm{mm}$.

zontal axis by an angle $\alpha$ (Fig. 1), which changes the orientation of the crack front relative to the applied shearing force, thereby changing the mode mixity ratio $K_{I I} / K_{I I I}$.

FEM computations with various crack front shapes were performed, using the same boundary conditions as in [33], in order to get the SIF profiles along the crack front for different values of $\alpha$. The sample was modeled using hexahedron elements of size $0.3 * 0.3 *$ $0.1 \mathrm{~mm}^{3}$ near the crack front, and the crack plane was modeled using XFEM representation with quadrilateral elements of size $0.1 * 0.01 \mathrm{~mm}^{2}$. SIFs were obtained using the $G$-Theta method [34]. The SIF distributions along the crack front were fitted with a $6^{\text {th }}$ order polynomial, omitting the corner nodes, where the SIFs were extrapolated from the polynomial to avoid corner point singularities [35]. Examples for a straight crack front are presented on figure 2. Although mode II dominates for $\alpha=0^{\circ}$ and mode III dominates for $\alpha=90^{\circ}$, the other mode is still present and exhibits a skew symmetric distribution. Each test thus provides kinetic data for several mode mixities, depending on the position along the crack front.

The experiments were performed on $R 260$ low alloy rail steel. Its composition and tensile properties are given table 1 and 2 respectively. The samples, which are $15 * 15 * 210 \mathrm{~mm}^{3}$ wide, were taken from the head of a new rail, and the crack plane was normal to the rail direction. The material is non textured, and exhibits a pearlitic microstructure (Fig. 3a), with an inter-lamellar spacing of a few hundreds of nanometers and a pearlite colonies size of a few tens of microns. It contains manganese sulfide inclusions $(\approx 5$ $\mu \mathrm{m}$ diameter and $\approx 100 \mu \mathrm{m}$ long) elongated in the rolling direction (Fig. 3b). Elastic-plastic constitutive equations using Lemaitre andChaboche's model [36] were identified, based on data from push pull and
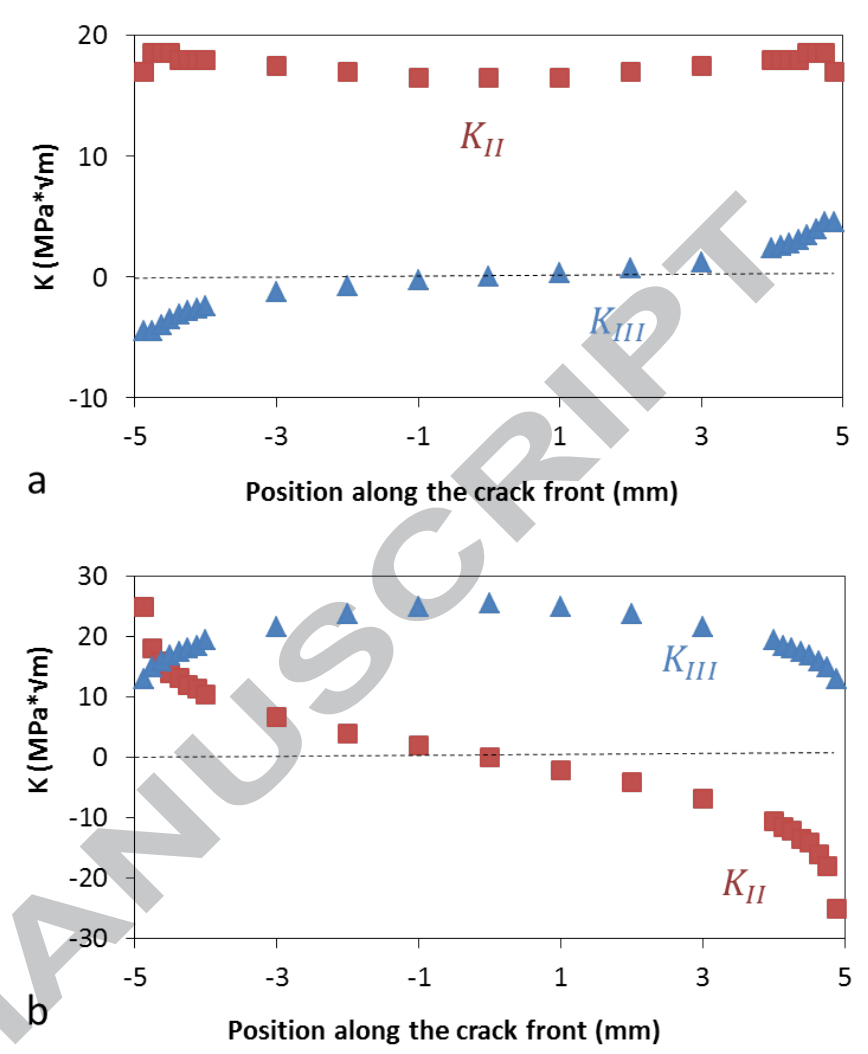

Figure 2: Stress intensity factors distribution for (a) $\alpha=0^{\circ}$ and (b) $\alpha=90^{\circ}$, assuming a straight crack front. The crack length is $a=4.6 \mathrm{~mm}$ and the applied force $F=34 \mathrm{kN}$.

cyclic torsion tests, as explained in Appendix A.

Table 1: Mass \% composition

\begin{tabular}{|c|c|c|c|c|}
\hline $\mathrm{C}$ & $\mathrm{Si}$ & $\mathrm{Mn}$ & $\mathrm{P}$ & $\mathrm{S}$ \\
\hline 0.72 & 0.32 & 1.08 & 0.015 & 0.022 \\
\hline
\end{tabular}

Table 2: Tensile properties

\begin{tabular}{|c|c|c|}
\hline $\mathrm{Rp}_{0,2}(\mathrm{MPa})$ & $\mathrm{Rm}(\mathrm{MPa})$ & $\mathrm{A} \%$ \\
\hline 480 & 880 & 10 \\
\hline
\end{tabular}

The specimens were pre-cracked at a constant $\Delta K_{I}$ $=16 \mathrm{MPa} \sqrt{m}$ with a load ratio $R=0.1$, and vacuum annealed for $4 \mathrm{~h}$ at $450^{\circ} \mathrm{C}$ in order to remove -as far as possible- the pre-cracking residual stresses, without changing the microstructure. Then, a small number of shear mode cycles (from 50 to 2000, depending on the loading range) were applied, at a constant loading range, with a load ratio $R=-1$ and a frequency 


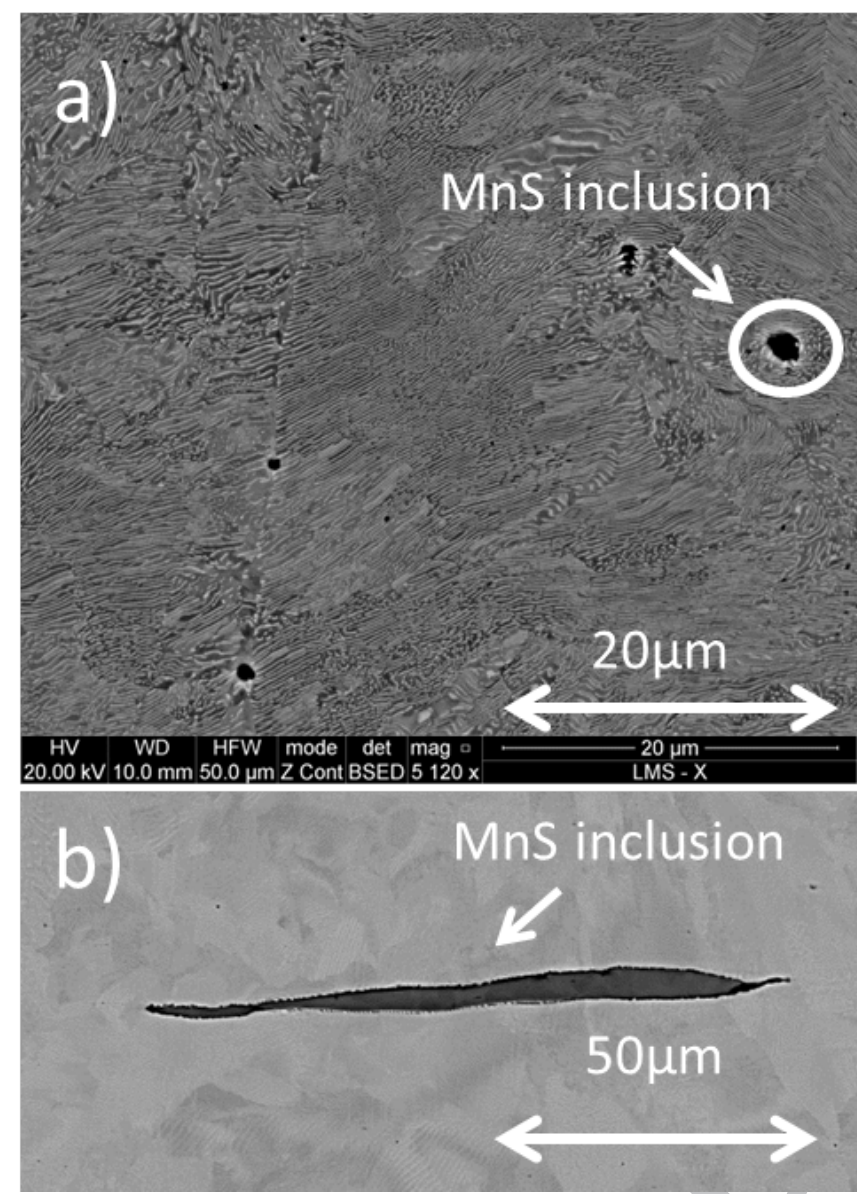

Figure 3: SEM image of the rail steel (a) in the plane perpendicular to the rolling direction and (b) in a plane containing the rolling direction using BSE.

of 2 cycles per minute. Table 3 summarizes the test conditions. The tests were periodically interrupted in order to cast replicas of the crack along the side surfaces. After bifurcation or coplanar growth over a few hundreds of micrometers, the specimens were broken either by mode I cyclic loading, or using liquid nitrogen-induced brittle impact fracture. In cases when SEM observations of the fracture surfaces revealed some coplanar shear-mode crack growth, the positions and shapes of the initial, slightly tunneling precracking front, and final, rather concave, shear mode crack fronts were determined (Fig. 4).

Since the monitoring of crack length evolutions on side surfaces did not reveal significant acceleration or deceleration during the limited number of applied shear-mode cycles (denoted by $\mathrm{N}$ ), a reasonable approximation of the local crack growth rate, at a given depth $z$ is deduced from the increment of crack length $\Delta a(z)$ at the corresponding depth (Fig. 4) at the end of the test.

$$
\frac{d a}{d N}(a, z) \approx \frac{\Delta a(z)}{\Delta N}
$$

Roughness measurements were performed on a few fracture surfaces, in two orthogonal directions, parallel or normal to the mean crack growth direction, using a mechanical profilometer Mitutoyo Surftest SJ-210.

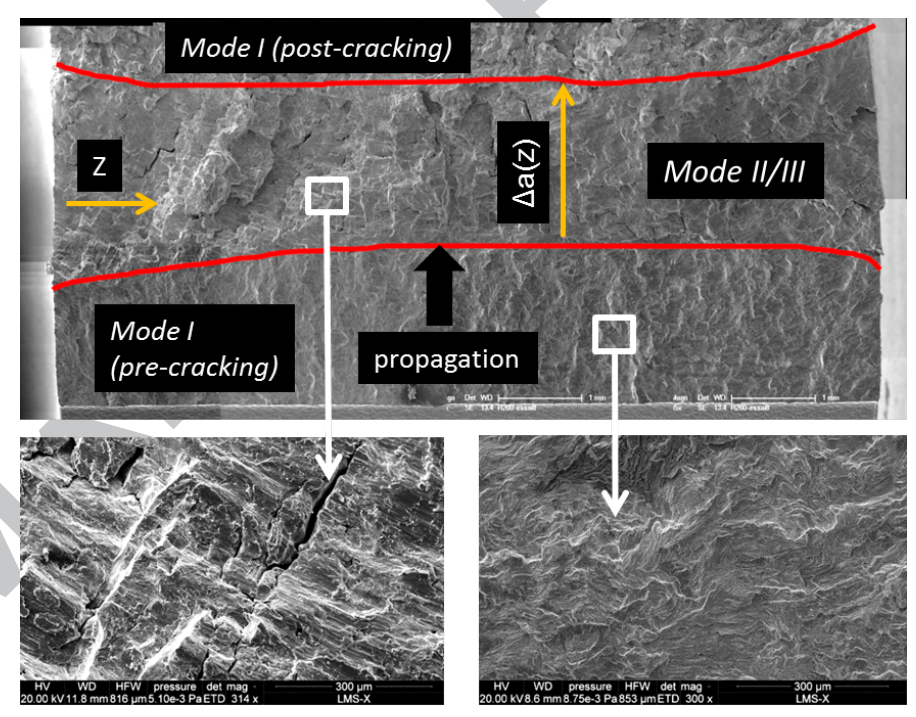

Figure 4: Initial and final shear mode crack fronts determined using SEM

In order to get Paris-like kinetic equations, it is necessary to determine the effective SIFs for each test, and each position along the crack front. Asperities interlocking and friction reduce the amplitude of crack face sliding displacements and the effective shear mode singularities at the crack front. The existence of such effects was confirmed here by the presence of wear debris on the fracture surfaces.

The determination of effective singularities relies on an inverse analysis of the crack opening and sliding displacement measured on the side surfaces, as detailed below. However, due to the position of the sample in the testing machine when the angle $\alpha$ is not equal to zero, the direct capture of images of both side surfaces is not feasible. Instead, plastic replicas are cast at maximum and minimum load, in order to get the sliding displacement range, but also at zero load, in order to measure the opening displacement range induced by the dilatancy effect. Due to crack face roughness, sliding of the crack leads to some open- 
ing, hence inducing two mode I sub-cycles inside one fully-reversed shear mode cycle [37], as illustrated on figure 5. To analyze it, the images captured at maximum and minimum load have to be correlated with that captured at zero load.

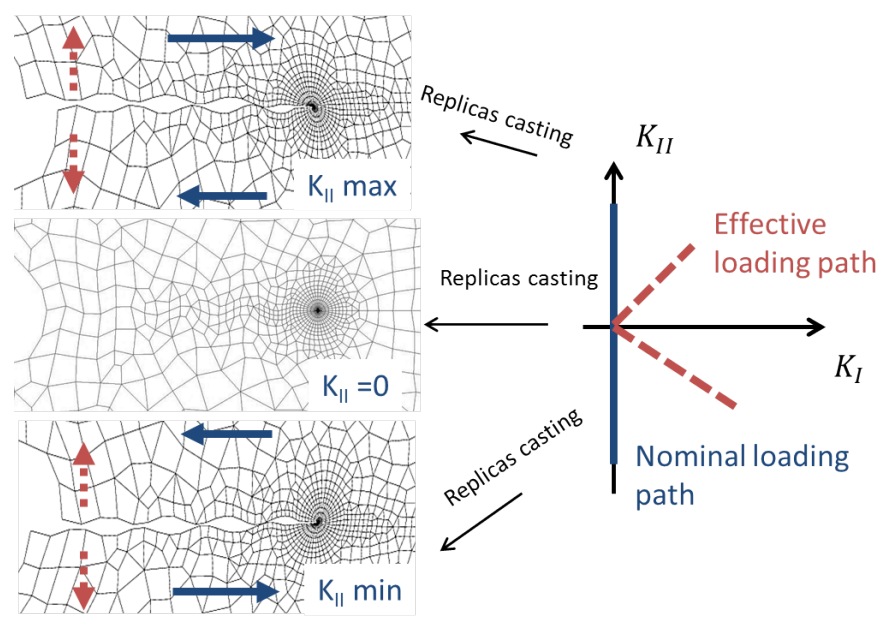

Figure 5: Nominal and effective path for a rough crack loaded in reversed mode $I I$ [37].

DIC is used to measure the in-plane opening and sliding displacements. Since the painted speckle pattern generally used for DIC is incompatible with replicas, sand blasting (with sand particles diameters from 1 to $50 \mu \mathrm{m}$ ) is used instead, in order to induce a topographic contrast on both side surfaces. A dense distribution of few micrometers wide craters forms a pattern visible with an atomic force microscope (AFM) or a digital optical microscope on the positive replicas cast from the plastic replicas. Two rows of virtual extensometers located $50 \mu \mathrm{m}$ above and below the crack (Fig. 6) are used to measure the inplane opening and sliding displacement jump profiles along the crack. The dilatancy $\Delta K_{I}$ is deduced from the slope of a plot (Fig. 7) of opening displacement range $\left[u_{y}\right](r)$ versus square-root distance to the crack tip, $\sqrt{r}$, using the relation given by Linear Elastic Fracture Mechanics for plane stress:

$$
\left[u_{y}\right](r)=\frac{8 \Delta K_{I}}{\sqrt{2 \pi} E} \sqrt{r}
$$

The out-of-plane sliding displacement profiles along the crack are measured on the positive replicas, using an AFM (fig. 8 a) for displacement ranges under 10 um. For greater displacement ranges, a topographic reconstruction is performed using a digital optical mi-

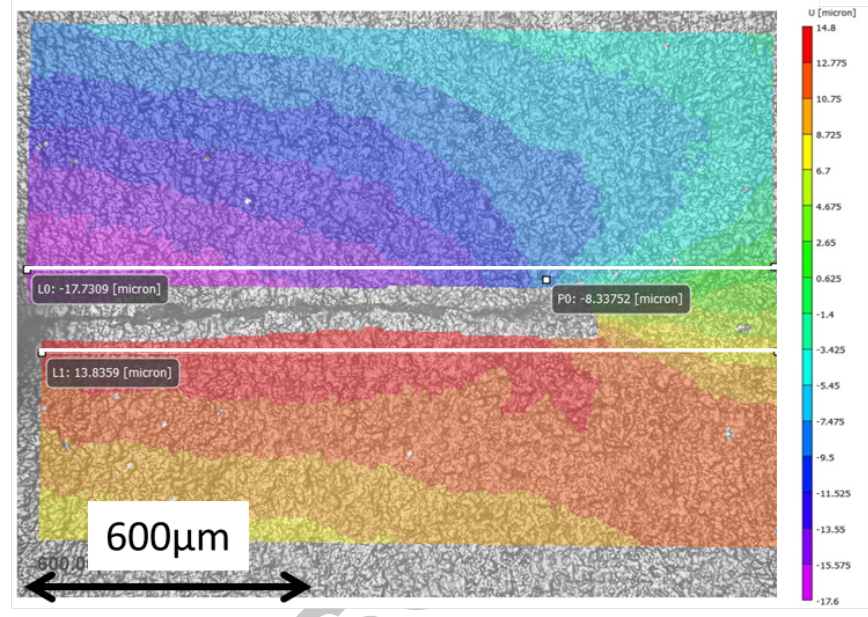

Figure 6: In-plane sliding displacement obtained by DIC (VIC2D). $Z O I=35 * 35$ pixels, 1pixel $=1 \mu \mathrm{m}$

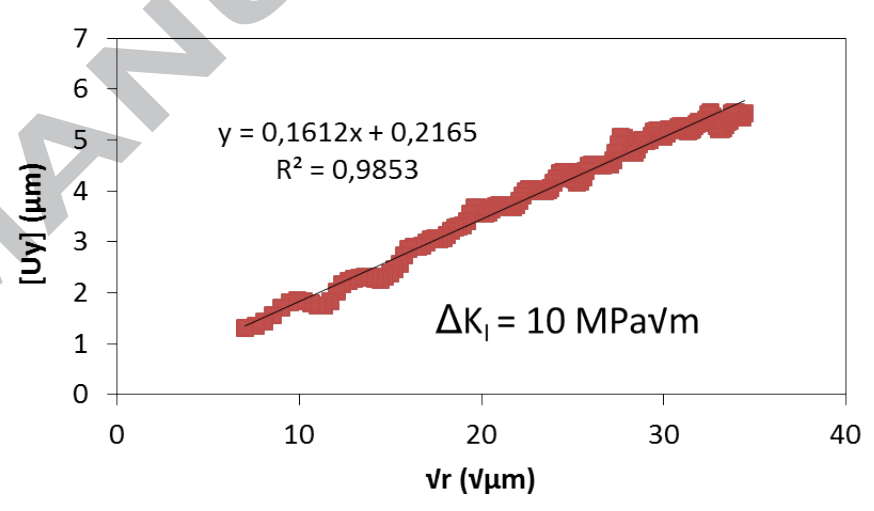

Figure 7: In-plane opening displacement versus $\sqrt{r} . \alpha=90^{\circ}$, $\pm 38 \mathrm{kN}$ loading range

croscope (fig. 8 b). Again, two rows of virtual extensometers $\pm 50 \mu \mathrm{m}$ above and below the crack are used to measure the out-of-plane displacement jump profile.

The effective fraction of the loading range is defined as:

$$
U_{i}=\Delta K_{i}^{\text {effective }} / \Delta K_{i}^{\text {nominal }}, i=I I, I I I
$$

This effective loading range is determined by comparing the experimental in-plane (mode II) and outof-plane (mode III) sliding displacement jump profiles to those computed for a frictionless crack. An elastic frictionless computation would neglect both the effects of crack tip plasticity, which increases the displacement jumps, and the effect of friction, which reduces it, and would not allow to separate those two 

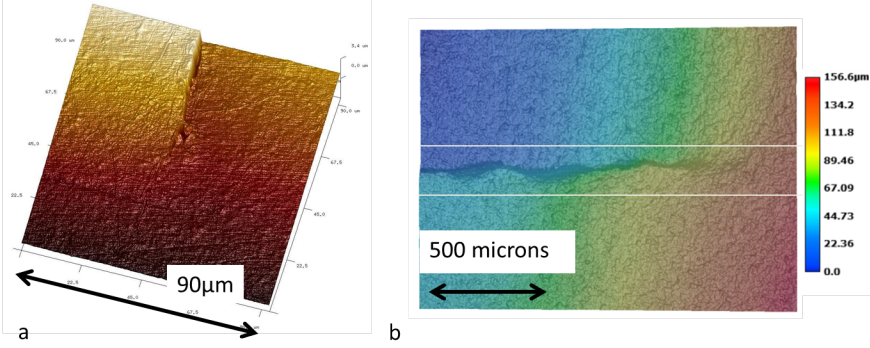

Figure 8: Out-of-plane sliding displacement obtained using an AFM (a), and topographic reconstruction with a digital optical microscope (b).

effects. In order to measure the influence of friction, elastic-plastic frictionless computations are run with various loading ranges to find the loading range which gives the best fit of the experimental sliding displacement, as illustrated in figure 9. This range is called the effective loading range, and allows an evaluation of the effective fraction of the loading range:

$$
U_{i}=\frac{\Delta F_{i}^{\text {effective }}}{\Delta F^{\text {applied }}}=\frac{\Delta K_{i}^{\text {effective }}}{\Delta K_{i}^{\text {nominal }}}, i=I I, I I I
$$

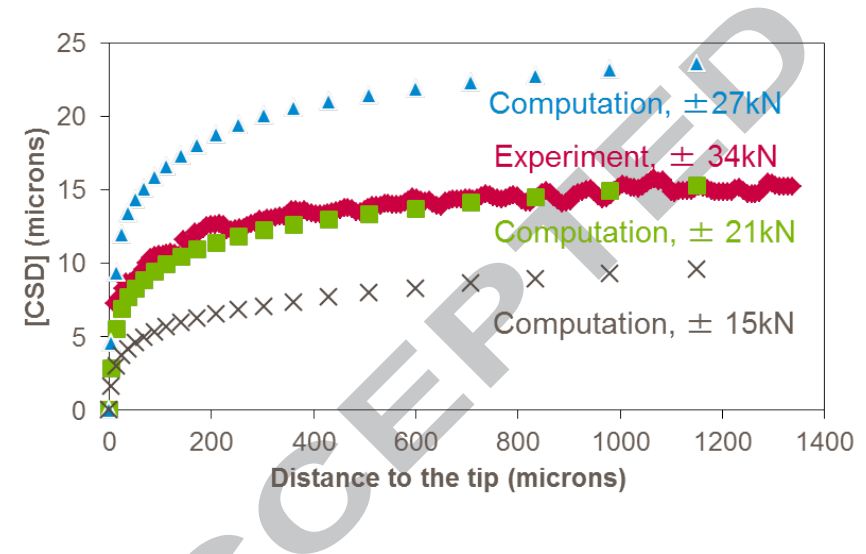

Figure 9: Comparison between the experimental in-plane sliding displacement jump and the computed ones for various loading ranges. The effective loading range is found to be $\pm 21 \mathrm{kN}$, while the applied one was $\pm 34 \mathrm{kN}$.

Within each test, the effective fraction of the loading range is found to be almost equal for both modes $\left(U_{I I} \approx U_{I I I}\right.$ with less than $15 \%$ difference) and on both side surfaces $\left(U_{\text {side } 1} \approx U_{\text {side2 }}\right.$ with less than $10 \%$ difference). A mean $U$ is thus computed for each test, and applied along the whole crack front, in order to get the effective SIFs from the nominal ones issued from FEM elastic, frictionless computations.

$$
\Delta K_{i}^{e f f}(z)=U_{\text {mean }} \Delta K_{i}^{\text {nom }}(z), i=I I, I I I
$$

For the computation of nominal SIFs, the slightly tunneling pre-crack front shape, as well as the concave final shear-mode crack front shape measured on the fracture surface were taken into account in the F.E. mesh.

\section{Experimental results}

\subsection{Crack paths}

Table 3 indicates the test results in terms of crack path. For small loading ranges, immediate crack kinking/twisting was observed along the whole crack front. For intermediate loading ranges, coplanar shear mode crack growth was observed only near the side surfaces, over a few hundreds of micrometers, while for high loading ranges, for which small-scale yielding conditions were however still fulfilled, coplanar shear mode crack growth was observed, along the whole crack front, over distances larger than $2 \mathrm{~mm}$.

During coplanar shear mode crack growth, branches orthogonal to the main crack line were observed on the replicas of the side surfaces, as illustrated on figure 10. Such secondary cracks leave traces more or less normal to the local crack growth direction on the fracture surfaces (Fig. 11a), and were also observed after mode II crack growth in austenitic steel by Pokluda et al (Fig. 7-10 in [20]) who attributed their nucleation to cyclic bending stresses on crack face asperities.

In mode II, a skew-symmetric singular stress parallel to the crack exists along the crack faces, so that after their nucleation, such orthogonal branches are loaded in cyclic mode I. The replicas cast at maximum (Fig. 10a), zero (Fig. 10b) and minimum load (Fig. 10c) clearly show that the orthogonal branch behind the main crack tip undergoes cyclic opening/closure. Such a phenomenon was first underlined by Kfouri [38] and analyzed in detail by Doquet \& Frelat [39]. In the latter study, the shielding effect of such branches on the main crack tip singularity was assessed, depending on their length and position behind the tip. For a fast propagating shear-mode crack, such a branch was predicted to grow in mode I at a decreasing rate, and to be left behind by the main crack, until it finally gets arrested, while for slower growth of the main crack in mode II, such a branch was predicted to develop faster than the main crack that stopped growing. These two cases can actually be observed on figure 10 . In addition to 
Table 3: Test conditions and results

\begin{tabular}{cccccc}
\hline$\alpha\left(^{\circ}\right)$ & load (kN) & $\begin{array}{c}\text { Number } \\
\text { of cycles } \\
\text { N }\end{array}$ & $\begin{array}{c}\text { Distance of coplanar } \\
\text { growth (surface 1) } \\
(\mu \mathrm{m})\end{array}$ & $\begin{array}{c}\text { Distance of coplanar } \\
\text { growth (surface 2) } \\
(\mu \mathrm{m})\end{array}$ & $\begin{array}{c}\text { Distance of coplanar } \\
\text { growth (mid } \\
\text { thickness) }(\mathrm{\mu m})\end{array}$ \\
\hline 90 & \pm 22 & 700 & 200 & $?$ & 0 \\
90 & \pm 28 & 1000 & 580 & 700 & 340 \\
90 & \pm 34 & 700 & 1200 & 1000 & 700 \\
90 & \pm 38 & 180 & 2800 & 2700 & 2000 \\
0 & \pm 30 & 2000 & 220 & 290 & $?$ \\
0 & \pm 35 & 500 & 500 & 250 & 190 \\
0 & \pm 39 & 600 & 350 & 300 & 135 \\
0 & \pm 42 & 120 & 405 & 485 & $?$ \\
0 & \pm 45 & 300 & 330 & 400 & 170 \\
0 & \pm 47 & 50 & 335 & 320 & 200 \\
0 & \pm 50 & 90 & 420 & 110 & \\
\hline
\end{tabular}

the aborted orthogonal branch left behind the tip, a branch formed at an angle of $90^{\circ}$ at the current tip above and below the main crack plane, and grew over approximately $100 \mu \mathrm{m}$, before kinking at $70^{\circ}$.

Branches were also formed in a plane normal to the crack front containing the local crack growth direction, as revealed by X-ray computed tomographic images (Fig. 12). The secondary cracks visible on the fracture surface in figure $11 \mathrm{~b}$ and nearly parallel to the local crack growth direction correspond to the same kind of branch. Such secondary cracks were also observed after mode III crack growth in austenitic steel by Pokluda et al (Fig 11-15 in [20]), who attributed their formation to cyclic bending stresses on crack face asperities, or to the occasional presence of second phase particles. The position of the branches at the bottom of asperities on figure 12 tends to support the first explanation, even though in rail steel, the presence of elongated manganese sulfide inclusions normal to the crack growth plane might also play a role in the initiation of such branch cracks. But whatever their nucleation mechanism, these branches might grow either due to the cyclic shear stress induced by the mode III component: $\sigma_{x z}=K_{I I I} / \sqrt{2 \pi r}$, or due to the cyclic opening stress associated with mode II, in plane strain: $\sigma_{z z}=$

$\nu K_{I I} / \sqrt{2 \pi r}$. Such branches probably also shield the main crack and may promote its bifurcation, although this deserves further analysis through 3D numerical simulation.

\subsection{Effective singularities}

In plane strain, the energy release rate $\mathrm{G}$ is related to $K_{I}, K_{I I}$ and $K_{I I I}$ by:

$$
G=\frac{1+\nu}{E}\left[(1-\nu)\left(K_{I}^{2}+K_{I I}^{2}\right)+K_{I I I}^{2}\right]
$$

In the following, the contribution of shear-modes to the energy release rate $\Delta K_{\text {shear }}$ is defined as:

$$
\Delta K_{\text {shear }}=\sqrt{(1+\nu)\left[(1-\nu) \Delta K_{I I}^{2}+\Delta K_{I I I}^{2}\right]}
$$

As mentioned above, the reversed sliding of rough crack face during one shear-mode cycle induces two mode I sub-cycles, which do not always have similar amplitudes (Fig. 5). The maximum amplitude of those two sub-cycles is denoted below as "dilatancy $\Delta K_{I}$ ". The measured dilatancy $\Delta K_{I}$ divided by $\Delta K_{\text {shear }}$ are plotted on figure 13 a as a function of the effective $\Delta K_{\text {shear }}$ divided by twice the mode $I$ toughness of the material, for confidentiality reasons. No systematic evolution appears, and the dilatancy $\Delta K_{I}$ lies between 15 and $25 \%$ of $\Delta K_{\text {shear }}$ for $\alpha=90^{\circ}$ (predominant mode III) and between 8 and $20 \%$ for $\alpha=0^{\circ}$ (predominant mode $I I$ ). The induced opening seems larger for predominant mode $I I I$. This is consistent with higher average roughness index $R a$ measured along series of lines parallel to the front ( $\langle R a\rangle=8.8 \mu \mathrm{m})$ than in the normal direction 

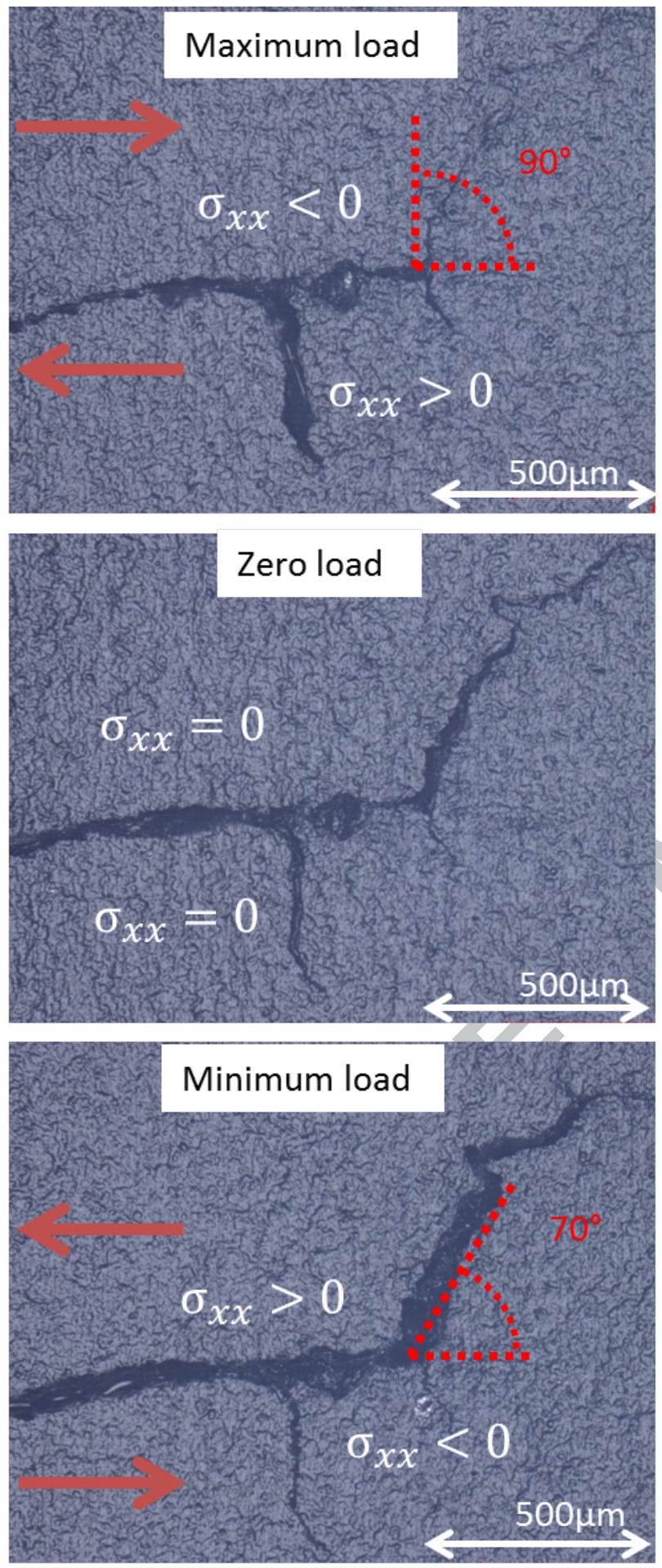

Figure 10: Replicas casted at maximum, zero and minimum load on a crack with branches, $\alpha=0^{\circ}$.

$(<R a>=5.9 \mu \mathrm{m})$. Higher asperities in the direction parallel to the front thus induce more crack opening when mode III dominates.

The effective fraction of the loading range, $U$, is
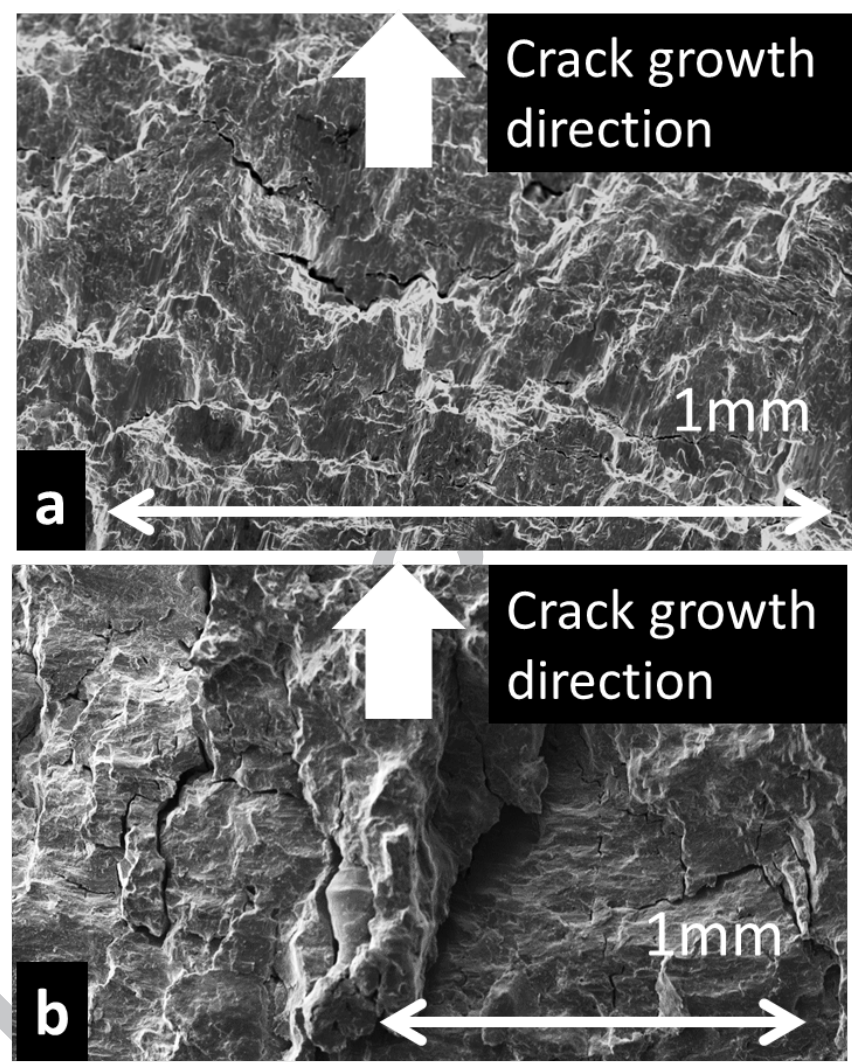

Figure 11: Secondary cracks on the fracture surfaces: a) nearly normal to the local crack growth direction where mode II dominates and b) nearly parallel to the local crack growth direction where mode III dominates.

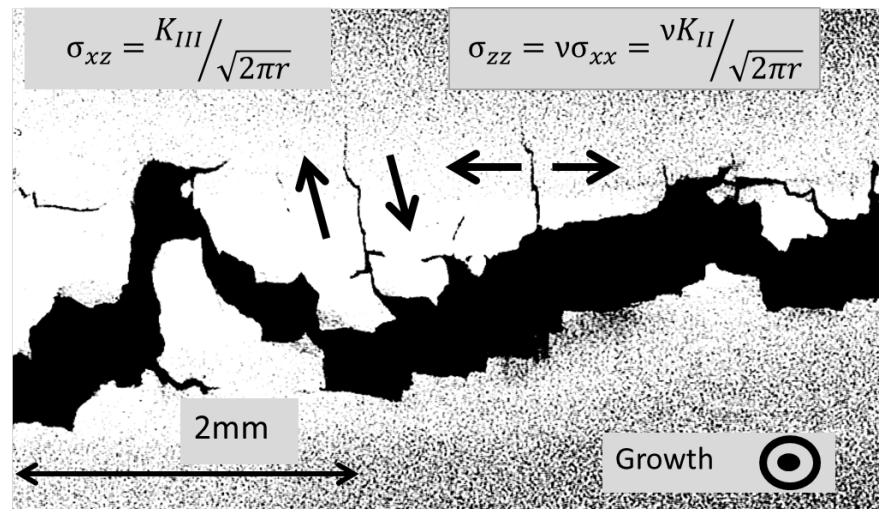

Figure 12: Branches in a plane normal to the crack front, $\alpha=$ $90^{\circ}$. Tomographic image, resolution $5 \mathrm{\mu m}^{3}$. The crack growth direction is normal to the image plane.

plotted versus the nominal $\Delta K_{\text {shear }}$ on figure $13 \mathrm{~b}$. It lies between 0.3 and 0.9 , which is comparable to the values measured on maraging steel and Ti- $6 \mathrm{Al}-4 \mathrm{~V}$ in [33] and on $65 \mathrm{G}$ steel in [12]. This ratio is larger for $\alpha=0^{\circ}$ than for $\alpha=90^{\circ}$, which is consistent with the results on the dilatancy opening (Fig. 13a) and with 
the higher roughness measured in the direction parallel to the front. While $U$ does not change much with $\Delta K_{\text {shear }}$ for $\alpha=0^{\circ}$, it increases with $\Delta K_{\text {shear }}$ for $\alpha=90^{\circ}$, meaning that the influence of friction tends to decrease as the loading range increases. This is consistent with the predictions of the model developed by Gross and Mendelsohn [40].
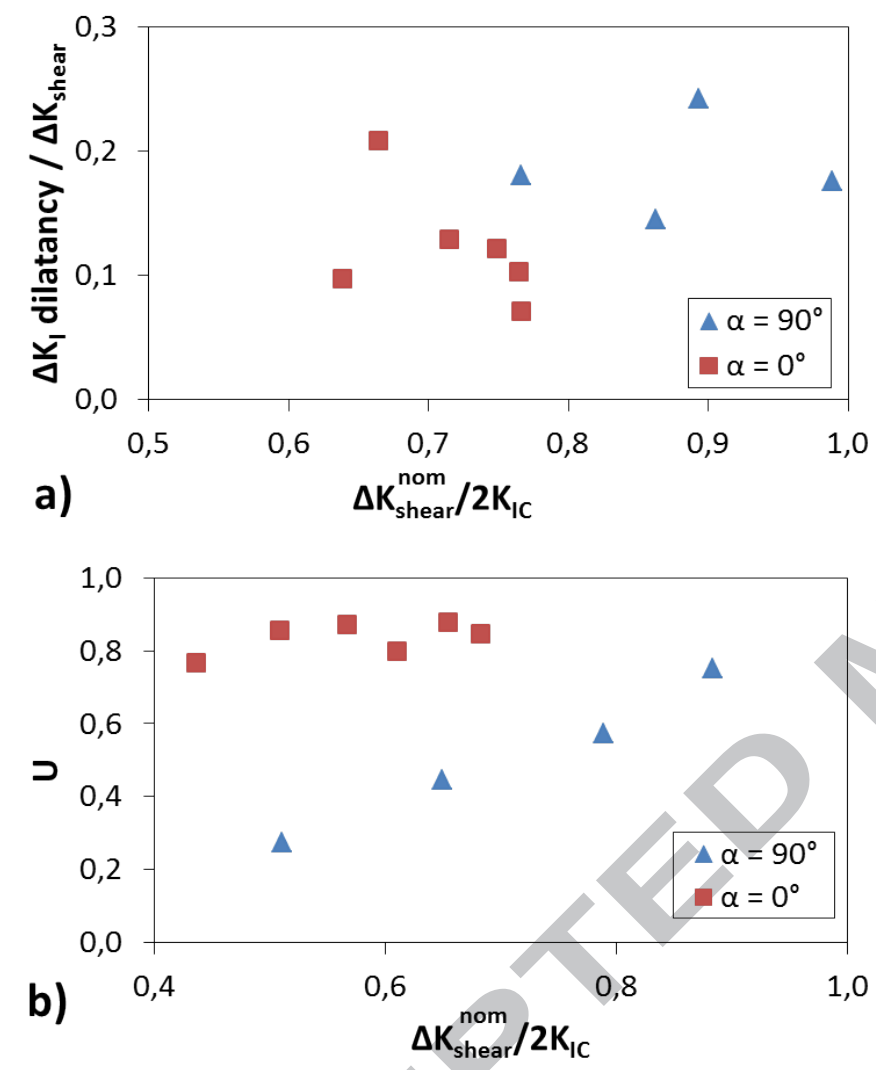

Figure 13: Evolution of $\Delta K_{I} / \Delta K_{\text {shear }}^{\text {nominal }}$ (a) and $U$ (b) as a function of $\Delta K_{\text {shear }}^{\text {nominal }} / 2 K_{I C}$

\subsection{Shear-mode crack growth kinetics}

The measured crack growth rates are plotted on figure 14 versus $\Delta G_{\text {shear }}^{e f f}$ and $\Delta G^{e f f}$ defined in equ.8 and 9 , respectively, and normalized by 4 times the critical energy release rate $G_{I C}$.

$$
\begin{gathered}
\Delta G_{\text {shear }}^{e f f}=\frac{1+\nu}{E}\left[(1-\nu) \Delta K_{I I}^{e f f^{2}}+\Delta K_{I I I}^{e f f^{2}}\right] \\
\Delta G^{e f f}=\frac{2 *\left(1-\nu^{2}\right)}{E} \Delta K_{I}^{2}+\Delta G_{\text {shear }}^{\text {eff }}
\end{gathered}
$$

The dilatancy $K_{I}$ is counted twice in equ.9 since there are two mode I sub-cycles within each reversed shear-mode cycle. Taking the induced opening into account does not increase the correlation coefficient $R^{2}$ when a power law is fitted.

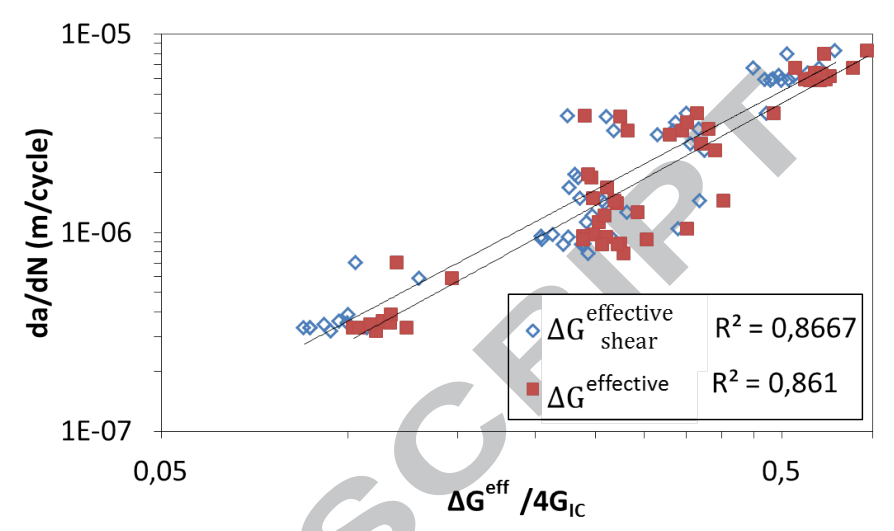

Figure 14: Crack growth rate as a function of $\Delta G^{\text {effective }}$ and $\Delta G^{\text {dilatancy }}$.

The influence of the dilatancy $\Delta K_{I}$ on crack growth kinetics was thus neglected in the following. An attempt to improve data correlation, by introducing an "equivalent" $\Delta K$ :

$$
\Delta K_{\text {equivalent }}^{\text {eff }}=\sqrt{\Delta K_{I I}^{e f f^{2}}+\beta \Delta K_{I I I}^{e f f^{2}}}
$$

and searching for the weighting coefficient $\beta$ corresponding to the highest correlation coefficient was made, as previously done in [33] and [23]. The best fit for a power law (Paris like equation) was obtained for $\beta \approx 1.25$, with $R^{2}=0.871$ (Fig. 15), which is only marginally better than the fit obtained using $\Delta G_{\text {shear }}^{\text {effective }}\left(R^{2}=0.867\right)$. The latter assumes that mode II and III are equivalent driving forces, and corresponds to $\beta$ equal to $1 /(1-\nu) \approx 1.39$. The value of $\beta$ found here suggests that mode III is slightly less efficient than mode II for coplanar shear-mode crack growth. The best value of $\beta$ found here is comparable to those found in [33] for Maraging steel $(\beta=1.2)$ and in [23] for ARMCO iron for near threshold propagation $(\beta=1.1)$.

\section{Modelling}

\subsection{Principle of the local approach}

The above-mentioned approach based on Linear Elastic Fracture Mechanics and a Paris-like kinetic equation allows satisfactory predictions of the crack growth rates in proportional mixed mode II \& III, but cannot be used in non proportional loading, as 


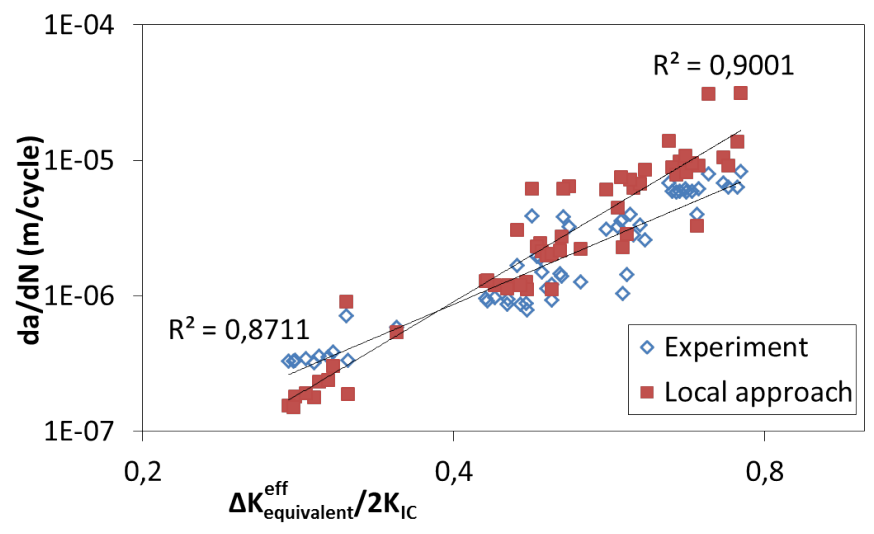

Figure 15: Experimental and predicted crack growth rate as a function of $\Delta K_{\text {equivalent }}$, with $\beta=1.25$.

shown by Fremy and Pommier [28]. Since crack propagation in railways involves non-proportional mixedmode I+II+III, an other approach is needed. This approach should not only take into account the synergistic effects of the three loading modes -related to coupled crack tip plasticity- in terms of crack growth rate, such as the approach used in [41], but also account for the potential existence of two different propagation mechanisms (shear or tension driven), which the latter approach does not do.

A local approach was proposed by Doquet and Bertolino [42] in order to determine the crack growth rates and crack paths. It is based on the evaluation of the cyclic stress and strain evolutions ahead of the crack tip from elastic-plastic FE simulations, followed by the application of two critical plane, shear-driven or tension-driven fatigue damage models, and the application of the maximum growth rate criterion. This method was used in [37] for non proportional mixed mode I + II on maraging steel, and was able to predict the crack path in almost all considered loading cases. This approach was also shown to capture the synergistic effects between mode I and mode II under sequential loading, for which the crack path was well predicted [42]. In [33], the same method was applied node by node along the front of cracks loaded in mixed mode II \& III in maraging steel and Ti$6 \mathrm{Al}-4 \mathrm{~V}$. A predictions of the crack path in $3 \mathrm{D}$ was however not attempted, but good predictions of the crack growth rate, -assumed to remain coplanar, as observed in the experiments- were obtained.

This approach is based on the idea that fatigue damage ahead of the crack tip is responsible for crack propagation, and that two damage mechanisms are competing, one accounting for shear mode and the other for tensile mode. Two damage parameters are thus used. The first one, proposed by Smith, Watson and Topper [43], -with the dimension of an energyaccounts for tension-driven damage:

$$
\beta_{S W T}=\Delta \epsilon_{n} * \sigma_{n, \max }
$$

In previous studies, [33, 37, 42], Fatemi and Socie's damage function -which is dimensionless- was used, to account for shear-driven damage:

$$
\beta_{F S}=\Delta \gamma_{\max }\left(1+k_{F S} \frac{\sigma_{n, \max }}{\sigma_{y}}\right)
$$

where $\sigma_{n, \max }$ denotes the peak opening stress on the facet which undergoes the maximum shear strain range, $\Delta \gamma$, and $k_{F S}$ is a dimensionless coefficient.

Alternatively, Findley's damage function -which has the dimension of a stress- could also be used:

$$
\beta_{\text {Find }}=\Delta \tau+k_{F I} * \sigma_{n, \max }
$$

where $k_{F I}$ is a dimensionless parameter.

However, in the present study, a shear-driven damage function equal to the product of the two previous ones, -and which thus has the dimension of an energy, like the tension-driven damage function- was preferred:

$$
\beta_{\text {Shear }}=\beta_{\text {Find }} * \beta_{F S}
$$

Those two damage functions are evaluated from elastic-plastic FE simulations, and averaged over a small segment of length $\Delta L$ in every possible direction (characterized by a tilt angle $\phi$ and a twist angle $\psi$ ) ahead of each node of the crack front. Contrary to the previous study on mixed-mode $I I+I I I$ [33] no assumption is thus made here on the crack path. The corresponding fatigue lives, $N_{f, \text { tension }}$ and $N_{f, \text { shear }}$, are deduced, using the equations fitted from lowcycle fatigue data, as explained in Appendix B. The minimum of those two values, $N_{f}=\min \left(N_{f, \text { tension }}\right.$, $N_{f, \text { shear }}$ ), as well as the associated direction are then extracted. The potential local crack propagation rate is evaluated as:

$$
\frac{d a}{d N} \approx \frac{\Delta L}{N_{f}}
$$

The crack is thus assumed to propagate according to the mechanism which maximizes its growth rate, 
which gives both the propagation direction and the crack growth rate.

This approach was applied on five of the experiments described above, which gave rise to some coplanar crack growth over the whole crack front. The effective loading range, corresponding to the measured sliding displacements, allowance made for friction effects, was applied in the F.E. computations, but the small mode I sub-cycles due to dilantancy were not simulated. When coplanar growth was predicted along the whole crack front, two FE computations were run: one with the initial, slightly tunneling crack front shape inherited from mode I precracking, and one with the final, slightly concave shear mode crack front measured on the fracture surfaces. The initial and final predicted crack growth rates were then averaged, and compared to the measured ones, which also correspond to a mean value over applied shear mode cycles.

The influence of the length $\Delta L$, on the predicted crack growth rates was evaluated. For $\Delta L=0.1 \mathrm{~mm}$ the predicted crack growth rates were at most $30 \%$ higher than for $\Delta L=0.04 \mathrm{~mm}$. The influence of this parameter is thus relatively limited. A value of $\Delta L=0.04 \mathrm{~mm}$, which corresponds to the length of 2 elements ahead of the crack tip appeared to give the best predictions of the crack growth rates, and was thus adopted.

\subsection{Predicted crack paths}

For the test run with an angle $\alpha=0^{\circ}$ and a loading range of $\pm 42 \mathrm{kN}$, the predicted coplanar, shearmode growth rate at mid-thickness -where pure mode II prevailed-was 4.8 times higher than that of a potential tilted branch crack, while for the test run at $\pm 47 \mathrm{kN}$ the ratio was 6.8 . The ratios were even higher near side surfaces. Coplanar shear-mode crack growth along the whole crack front was thus predicted in both cases, in accordance with the experimental observations.

For the test run with an angle $\alpha=90^{\circ}$ and loading ranges of $\pm 28 \mathrm{kN}, \pm 34 \mathrm{kN}$ and $\pm 38 \mathrm{kN}$, the predicted coplanar shear-mode growth rates at mid-thickness where pure mode III prevailed- were respectively 1.6, 3.1 , and 5 times higher than those of a potential twisted branch crack. Again, coplanar shear-mode crack growth was thus predicted, in accordance with the experimental observations. However, the bifurcation witnessed after a few hundred micrometers of coplanar growth, and attributed to the formation of branches behind the crack front, and to a resulting shielding effect, not taken into account in the model, are not predicted.

Simulations were run for $\alpha=0^{\circ}$ and $\alpha=90^{\circ}$ with several loading ranges, in order to determine the effective threshold $\Delta K_{I I}$ or $\Delta K_{I I I}$ below which no coplanar shear-mode crack growth is expected at mid-thickness, but rather crack tilting or twisting, respectively. The predicted threshold for coplanar growth at mid-thickness for $\alpha=90^{\circ}$ (mode III) is $(0.35 \pm 0.04) K_{I C}$, which is quite consistent with the experimentally determined range $(0.37 \pm 0.13) K_{I C}$ (Table 4). For $\alpha=0^{\circ}$, the predicted threshold for coplanar growth at mid-thickness (mode II) is $(0.26 \pm$ $0.0 .3) K_{I C}$, but available experimental data are not sufficient for an accurate determination of this threshold so that a comparison is not possible.

\subsection{Predicted crack growth rates}

The predicted and measured coplanar crack growth rates profiles along the crack front are compared on fig. 16 for 3 tests run at an angle of $\alpha=90^{\circ}$, and on fig. 17 for 2 tests run at an angle $\alpha=0^{\circ}$. The crack growth rate is overestimated at the corner points by a factor up to 3.9, while at mid-thickness, the evaluated crack growth rates are within a factor 2 above or below the measured ones. Given the uncertainties on the local crack growth rates (the final shear mode crack fronts are sometimes difficult to locate accurately, especially near the side surfaces), as well as the uncertainties on the effective loading ranges, those predictions can be considered as successful. This is also illustrated by the comparison of the plot of predicted growth rates versus $\Delta K_{\text {equivalent }}$ with the experimental one, on fig. 15 .

\section{Conclusions}

- Mode II + III coplanar fatigue crack growth was observed over distances up to $2.8 \mathrm{~mm}$ in R260 rail steel. For mode III, the effective threshold for coplanar shear-mode growth rather than bifurcation was $(0.37 \pm 0.13) K_{I C}$.

- Even when coplanar shear mode crack growth was witnessed, branch cracks formed normal 
Table 4: Exprimental and computed thresholds

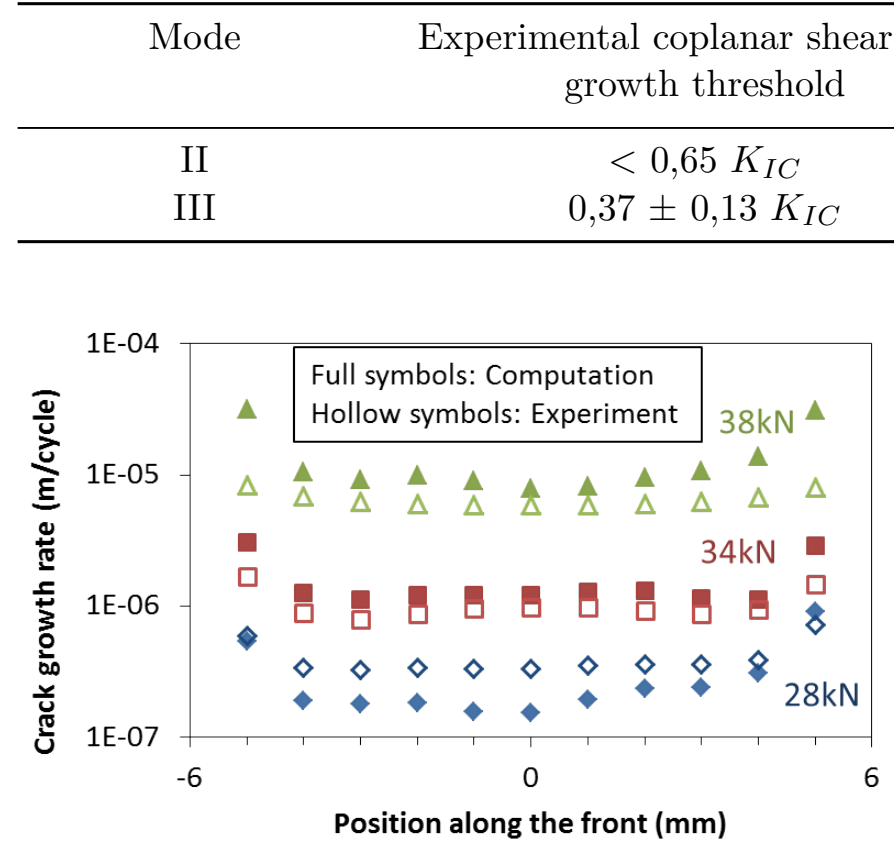

Figure 16: Experimental and computed crack growth rates along the crack front for $\alpha=90^{\circ}$.

to the main crack plane and shielded its tip, thereby leading to its bifurcation.

- Due to crack faces interlocking and friction, the effective fraction of the loading range $U$ was between 0.3 and 0.9 .

- Sliding of rough crack faces induced two mode I sub-cycles within each reversed shear mode cycle. The resulting dilatancy $\Delta K_{I}$ was between 0.08 and $0.25 \Delta K_{\text {shear }}$.

- The best fit for a Paris-like equation was found for $\Delta K_{\text {equivalent }}=$

$$
\sqrt{\Delta K_{I I}^{\text {effective }^{2}}+1.25 \Delta K_{I I I}^{\text {effective }}{ }^{2}}
$$

meaning that mode III is slightly less efficient than mode II for coplanar shear mode propagation.

- Reasonable predictions of the shear-mode crack growth rates, as well as the threshold for coplanar shear mode propagation (rather than twisting or tilting) were obtained using a local approach. This approach is based on the local application, ahead of each node of the crack

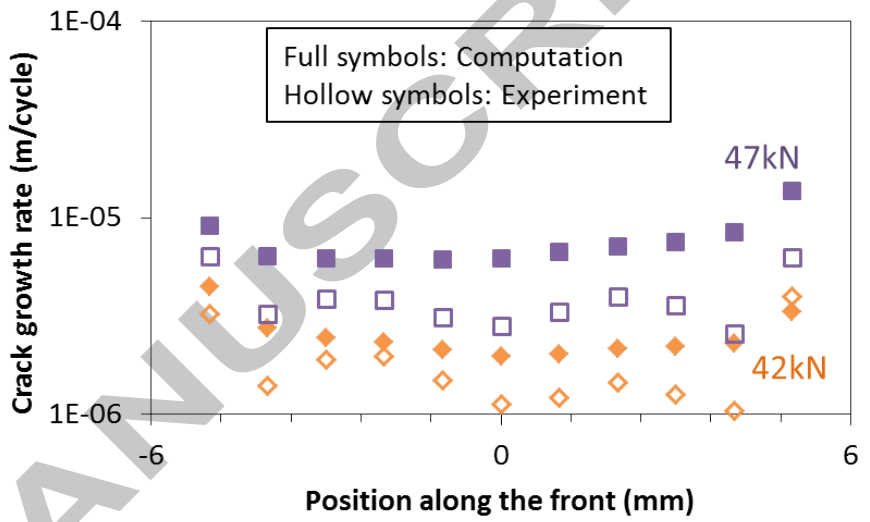

Figure 17: Experimental and computed crack growth rates along the crack front for $\alpha=0^{\circ}$.

front -after elastic-plastic computations of local stress and strain ranges- of a shear-driven and a tension driven fatigue damage models. A 3D search for the direction in which failure of a small segment occurs first, by one mechanism or the other, is then performed to get the maximum crack growth rate and the associated direction.

- Sand blasting was shown to be a simple and effective surface marking technique for DIC.

\section{Acknowledgements}

The authors would like to acknowledge SNCF for its financial support and British Steel for providing the rail steel. Dr Patrick Aimedieu from the Navier laboratory of the ENPC is also acknowledged for his help in tomographic imaging.

\section{Appendix A. Identification of constitutive equa- tions}

The stress-strain curves recorded during straincontrolled push-pull and cyclic torsion tests were fed to a Levenberg-Marquardt algorithm in order to fit 
constitutive equations using isotropic and one or two kinematic hardening variables, according to Lemaitre and Chaboche's model [36]:

$$
\begin{gathered}
f=J_{2}\left(\underline{\underline{\sigma}}-\underline{\underline{X_{1}}}-\underline{\underline{X_{2}}}\right)-R \\
d \underline{\underline{X_{i}}}=C_{i} *\left(\frac{2}{3} * A_{i} * d \underline{\underline{\epsilon_{p}}}-\underline{\underline{X_{i}}} * d p\right) \\
R=R_{0}+\left(R_{M}-R_{0}\right) *\left(1-e^{-b * p}\right) \\
d \epsilon_{p}=d \lambda * \frac{\partial f}{\partial \underline{\underline{\sigma}}}
\end{gathered}
$$

where $\mathrm{f}$ is the yield function, $X_{1}$ and $X_{2}$ are the kinematic hardening variables, $\mathrm{R} \overline{\overline{\text { the }}}$ isotropic hardening variable, $p$ the accumulated plastic strain, $\lambda$ the plastic multiplier, and $C_{1}, C_{2}, A_{1}, A_{2}, R_{0}, R_{M}$, and $b$ are material coefficients.

The materials shows nearly no isotropic hardening (the parameters $R_{0}$ and $R_{m}$ are equal), and one kinematic variable is enough to get a good prediction of the behavior, as shown on figures A.18 and A.19.

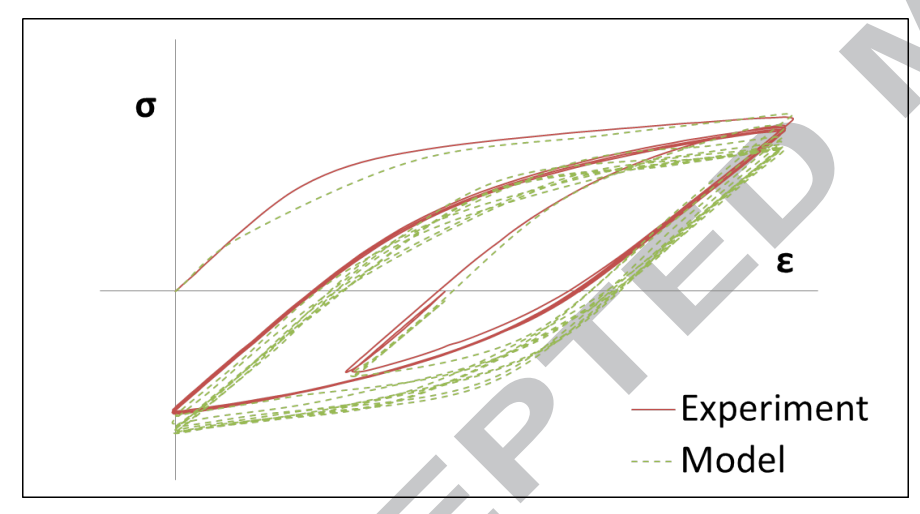

Figure A.18: Experimental and fitted curve for a push-pull cyclic test, $R=0$ and $\Delta \epsilon=0.8$. No units for confidentiality reasons.

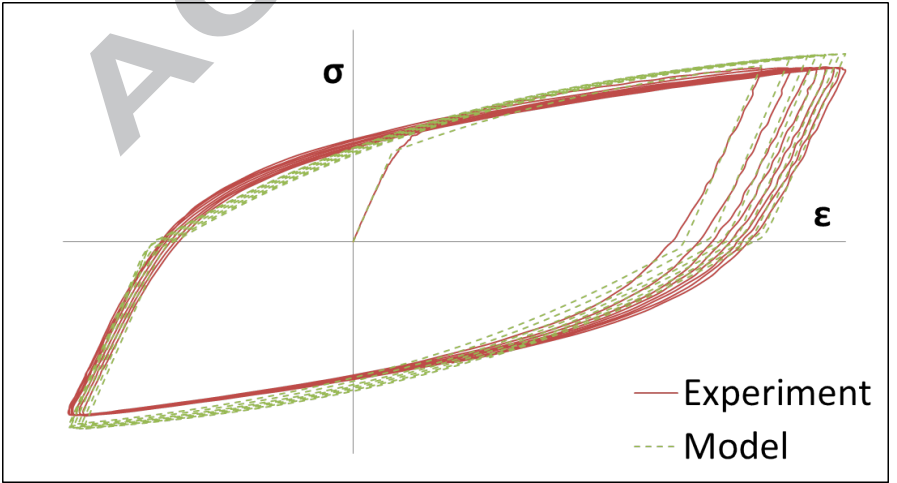

Figure A.19: Experimental and fitted curve for a torsion cyclic test, $R=-1$ and $\Delta \tau=820 \mathrm{MPa}$. No units for confidentiality reasons.
Table A.5: Parameters of the Lemaitre and Chaboche's model. For confidentiality reasons, some parameters are divided by the yield strength $\sigma_{Y}$ (different from $R_{p 0.2}$ ).

\begin{tabular}{|r|l|l|l|l|l|l|}
\hline$E(\mathrm{GPa})$ & $\nu$ & $\frac{A}{\sigma_{Y}}$ & $C$ & $\frac{R_{0}}{\sigma_{Y}}$ & $\frac{R_{m}}{\sigma_{Y}}$ & $b$ \\
\hline 202 & 0.29 & 2.48 & 94 & 1.84 & 1.84 & $/$ \\
\hline
\end{tabular}

\section{Appendix B. Identification of tension or shear-driven fatigue damage models.}

Analytical relations between the fatigue damage functions described in equ.11, 12, 13 and the number of cycles to failure (corresponding to a complete sample separation) were obtained based on several low-cycle fatigue tests.

Nine strain-controlled push-pull tests with various load ratios and a strain range between 0.2 and $2 \%$, corresponding to a range of fatigue lives between 944 and 38500 cycles were run. The number of cycles to failure was found to be a power function of Smith, Watson and Topper's damage function [43] minus a threshold value (equ. B.1), which allows a non propagation threshold to be predicted in the local approach.

$$
N r=a_{S W T} *\left(\beta_{S W T}-\beta_{S W T, t h r e s h o l d}\right)^{m_{S W T}}
$$

Fifteen cyclic torsion or cyclic torsion + static tension tests with various loading ranges and tensile stresses were run, in a range of fatigue lives between 72 and 53601 cycles. Failure always occurred due to shear-mode crack growth. Again, the number of cycles to failure was found to be a power function of the shear damage function minus a threshold (equ. B.2).

$$
N r=a_{\text {shear }} *\left(\beta_{\text {shear }}-\beta_{\text {shear }, \text { threshold }}\right)^{m_{\text {shear }}}
$$

The obtained curves are shown figure B.20, and the parameters are given table B.6. 


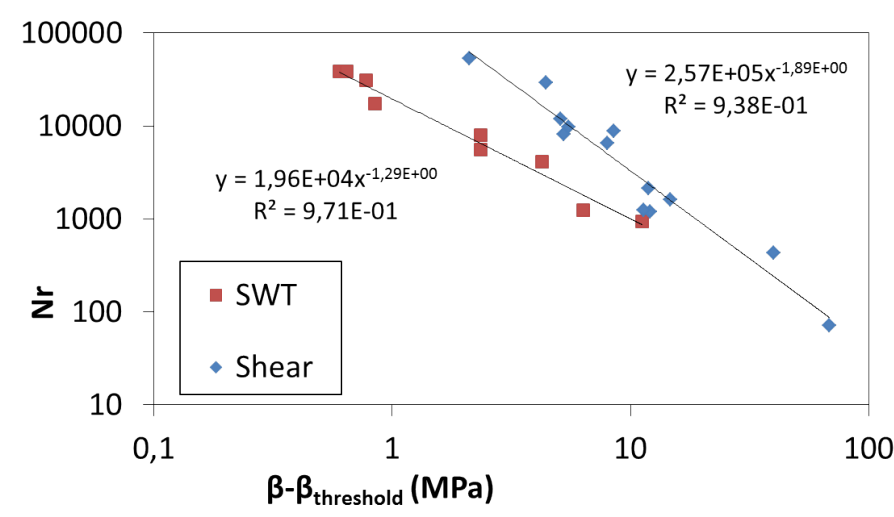

Figure B.20: Number of cycles to failure against the damage functions given equ.11 and 14, for push-pull and shear experiments respectively.

Table B.6: Parameters of the number of cycles to failure - damage laws (equ.B.1 and B.2).

\begin{tabular}{|l|l|l|r|}
\hline Criterion & $\mathrm{a}$ & $\mathrm{m}$ & $\beta_{\text {threshold }}$ \\
\hline SWT & 19567 & -1.292 & 1.2 \\
\hline shear & 256529 & -1.891 & 2.2 \\
\hline
\end{tabular}

\section{References}

[1] S. L. Wong, P. E. Bold, M. W. Brown, R. J. Allen, A branch criterion for shallow angled rolling contact fatigue cracks in rails, Wear 191 (1996) 45-53.

[2] S. Bogdanski, M. Olzak, J. Stupnicki, Numerical modelling of a $3 \mathrm{~d}$ rail rcf 'squat'-type crack under operating load, FFEMS 21 (1998) 923-935.

[3] S. H. Mai, A. Gravouil, M. L. Nguyen-Tajan, B. Trolle, Numerical simulation of rolling contact fatigue crack growth in rails with the rail bending and the frictional contact, Eng. Fract. Mech 174 (2017) 196-206.

[4] M. Schilke, N. Larijani, C. Persson, Interaction between cracks and microstructure in three dimensions for rolling contact fatigue in railway rails, FFEMS 37 (2014) 280289 .

[5] B. Dylewski, M. Risbet, S. Bouvier, Experimental Characterization of the Tridimensional Gradient of Microstructure Induced by RCF in the Rolling Band of Rails, Procedia Engineering 133 (2015) 202-210.

[6] F. Erdogan, G. C. Sih, On the crack extension in plates under plane loading and transverse shear, Basic engineering 85 (1963) 519-525.

[7] A. Otsuka, K. Mori, T. K, Mode ii fatigue crack growth in aluminium alloys, Current Research on Fatigue Cracks (1987) 149-180.

[8] M. C. Smith, R. A. Smith, Toward an understanding of mode II fatigue crack growth, Basic Questions in Fatigue 1 (1988) 260-280.

[9] Y. Murakami, S. Hamada, A new method for the measurement of mode II fatigue threshold stress intensity factor range, FFEMS 20 (6) (1997) 863-870.

[10] C. Pinna, V. Doquet, Preferred fatigue crack propagation mode in a M250 maraging steel loaded in shear, FFEMS 22 (3) (1999) 173-183.

[11] V. Doquet, G. Bertolino, A material and environmentdependent criterion for the prediction of fatigue crack paths in metallic structures, Eng Fract Mech 75 (2008) 3399-3412.

[12] T. M. Lenkovs'kyi, Influence of the Friction of Crack Faces on the Cyclic Crack-Growth Resistance of $65 \mathrm{G}$ Steel Under Mode II Loading, Materials Science 50 (5) (2015) 682686.

[13] Y. L. Ivanyts'kyi, T. M. Lenkovs'kyi, I. A. Verhun, S. T. Shtayura, Investigation of the Kinetics of Fatigue Macrocracks Under Transverse Shear, Materials Science 52 (3) (2016) 349-356.

[14] R. Ritchie, F. McClintock, H. Nayeb-Hashemi, M. Ritter, Mode III fatigue crack propagation in low alloy steel, Metallurgical Transactions A 13 (1) (1982) 101-110.

[15] E. K. Tschegg, Mode III and Mode I fatigue crack propagation behaviour under torsional loading, Journal of Materials Science 18 (6) (1983) 1604-1614.

[16] H. Nayeb-Hashemi, F. A. Mcclintock, R. O. Ritchie, Micro-mechanical modelling of mode III fatigue crack growth in rotor steels, Int J Fracture 23 (3) (1983) 163185.

[17] M. W. Brown, E. Hay, K. J. Miller, Fatigue at notches subjected to reversed torsion and static axial loads, FFEMS 8 (3) (1985) 243-258.

[18] T. S. Gross, Y. Zhang, D. W. Watt, Fracture Surface Interference in Shear-II. Experimental Measurements of Crack-Tip Displacement Field under Mode-II Loading in 7075-T6 A1, Acta Metallurgica et Materialia 43 (1995) 901-906.

[19] M. Brown, K. Miller, V. Fernando, J. Yates, Aspects of multiaxial fatigue crack propagation, in: 4th International conference biaxial/multiaxial fatigue, Paris, 1994, pp. 316.

[20] J. Pokluda, G. Trattnig, C. Martinschitz, R. Pippan, Straightforward comparison of fatigue crack growth under modes II and III, Int J Fatigue 30 (2008) 1498-1506.

[21] T. Vojtek, R. Pippan, A. Hohenwarter, L. Holan, J. Pokluda, Near-threshold propagation of mode II and mode III fatigue cracks in ferrite and austenite, Acta Materialia 61 (2013) 4625-4635.

[22] J. Pokluda, R. Pippan, T. Vojtek, A. Hohenwarter, Nearthreshold behaviour of shear-mode fatigue cracks in metallic materials, FFEMS 37 (2014) 232-254.

[23] T. Vojtek, J. Pokluda, P. Šandera, J. Horníková, A. Hohenwarter, R. Pippan, Analysis of fatigue crack propagation under mixed mode II + III in ARMCO iron, Int J Fatigue 76 (2015) 47-52.

[24] T. Vojtek, J. Pokluda, A. Hohenwarter, R. Pippan, Progress in understanding of intrinsic resistance to shearmode fatigue crack growth in metallic materials, Int J Fatigue 89 (2015) 36-42.

[25] T. Vojtek, J. Pokluda, A. Hohenwarter, R. Pippan, Intrinsic Behaviour of Modes II, III and Mixed Mode II+III Fatigue Cracks in Metallic Materials, in: ICMFF 11, Seville, 2016.

[26] T. Vojtek, J. Pokluda, P. Šandera, J. Horníková, A. Hohenwarter, R. Pippan, Analysis of fatigue crack propagation under mixed mode II + III in ARMCO iron, Int J Fatigue 76 (2015) 47-52. 
[27] T. Vojtek, A. Hohenwarter, R. Pippan, J. Pokluda, Experimental evidence of a common local mode II growth mechanism of fatigue cracks loaded in modes II, III and II+III in niobium and titanium, Int J Fatigue 92 (2016) 470-477.

[28] F. Fremy, S. Pommier, M. Poncelet, B. Raka, E. Galenne, S. Courtin, J. C. L. Roux, Load path effect on fatigue crack propagation in I + II + III mixed mode conditions - Part 1: Experimental investigations, Int J Fatigue 62 (2014) 104-112.

[29] A. K. Hellier, D. J. H. Corderoy, M. B. McGirr, A practical mixed Mode II/III fatigue test rig, Int J Fatigue 9 (1987) 95-101.

[30] A. K. Hellier, M. B. McGirr, D. J. H. Corderoy, A finite element and fatigue threshold study of shelling in heavy haul rails, Wear 144 (1991) 289-306.

[31] A. K. Hellier, K. Zarrabi, A. A. Merati, On the mode II fatigue threshold for mild steel, Int J Fract 167 (2011) $267-272$.

[32] A. A. Merati, A. K. Hellier, K. Zarrabi, On the mixed Mode II/III fatigue threshold behaviour for aluminium alloys 2014-T6 and 7075-T6, FFEMS 35 (2012) 2-12.

[33] V. Doquet, Q. H. Bui, G. Bertolino, E. Merhy, L. Alves, $3 \mathrm{D}$ shear-mode fatigue crack growth in maraging steel and Ti-6Al-4V, Int J Fracture 165 (2010) 61-76.

[34] P. Destuynder, S. Lescure, M. Djaoua, Some remarks on elastic fracture mechanics, Journal de mécanique théorique et appliquée 2 (1983) 113-135.

[35] Z. P. Bazant, L. F. Estenssoro, Surface singularity and crack propagation, Int J Solids Struct. 15 (1979) 405-426.

[36] J. Lemaitre, J.-L. Chaboche, Mechanics of solid materials, Cambridge university press, 1994.

[37] V. Doquet, M. Abbadi, Q. H. Bui, A. Pons, Influence of the loading path on fatigue crack growth under mixedmode loading, Int J Fracture 159 (2009) 219-232.

[38] A. P. Kfouri, A crack in a linear-elastic material under mode ii loading, revisited, FFEMS 22 (5) (1999) 445-448.

[39] V. Doquet, J. Frelat, Branch crack development from the flank of a fatigue crack propagating in mode II, FFEMS 24 (3) (2001) 207-214.

[40] T. S. Gross, D. A. Mendelsohn, Mode I stress intensity factors induced by fracture surface roughness under pure mode III loading: Application to the effect of loading modes on stress corrosion crack growth, Metallurgical Transactions A 20 (10) (1989) 1989-1999.

[41] F. Fremy, S. Pommier, E. Galenne, S. Courtin, J.-C. Le Roux, Load path effect on fatigue crack propagation in I + II + III mixed mode conditions - Part 2: Finite element analyses, Int J Fatigue 62 (2014) 113-118.

[42] V. Doquet, G. Bertolino, Local approach to fatigue cracks bifurcation, Int J Fatigue 30 (2008) 942-950.

[43] K. Smith, P. Watson, T. Topper, A stress-strain function for the fatigue of metals, J Mater 5 (1970) 767-778. 
Intrinsic Mode $I I+I I I$ fatigue crack growth kinetics in rail steel was obtained

Crack face interactions reduced the effective loading range by up to $70 \%$

A dilatancy effect induced mode $I$ cycles with $\Delta K_{I}$ between 8 and $25 \%$ of $\Delta K_{\text {shear }}$

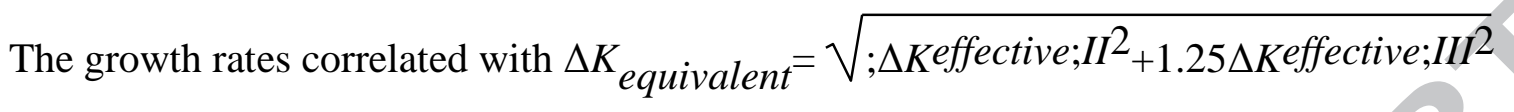

A method to predict the threshold for shear-mode growth and its rate was proposed 